\title{
Epstein-Barr Virus Infection associated with Acute Recurrent Laryngeal Nerve Palsy
}

\author{
Schwarze HP, Scholtz LU, Sudhoff H \\ Department of Otorhinolaryngology, Head and Neck Surgery, Teutoburger Str 50, D 33604 Bielefeld, Germany
}

Correspondence: Schwarze HP, Department of Otorhinolaryngology, Head and Neck Surgery, Klinikum Bielefeld, Teutoburger Street 50, D 33604 Bielefeld, Germany, Phone: 49(0521) 581-3301, Fax: 49 (0521) 581-3399, e-mail: schwarzemd@yahoo.com

\begin{abstract}
Introduction: Epstein-Barr virus (EBV) belongs to the group of human herpes viruses and can cause the clinical syndrome of infectious mononucleosis. EBV infection has been reported to cause several neurological complications. However, cranial nerve deficits are rare and have been infrequently reported. To our knowledge, recurrent laryngeal nerve palsy in EBV acutely infected patients has been reported only once with a case of bilateral laryngeal nerve palsy.

Case presentation: A case of a 41-year-old female Caucasian patient with a positive serology of active EBV infection developing acute recurrent laryngeal nerve palsy is presented. Fiberoptic rhinolaryngoscopy with stroboscopy showed complete paralysis of the left vocal cord in abduction with abundant secretions, consistent with unilateral recurrent laryngeal nerve paralysis. Full recovery over a 6-month follow-up period has been achieved by starting immediate speech therapy.

Conclusion: Our case report confirms the possible involvement of EBV infection in recurrent laryngeal nerve palsy. This rarely described association should be taken into account as an extremely rare differential diagnosis in patients suffering from recurrent laryngeal nerve paralysis and fatigue symptoms with muscle pain. To minimize the risk of permanent palsy, immediate speech therapy is recommended.
\end{abstract}

Keywords: EB virus, Recurrent laryngeal nerve palsy.

\section{INTRODUCTION}

Epstein-B arr virus (EB V) infection has been reported to cause neurological complications, such as meningoencephalitis, meningitis, acute inflammatory polyneuropathy (Guillain-Barré syndrome), B ell's palsy, lumbosacral radiculoplexopathy, recurrent polyneuropathies and optic neuritis (CR acute palsy). ${ }^{1-3}$ Less common complications comprise hemi plegic migraine syndrome, Reye syndrome and generalized chorea. ${ }^{4,5} \mathrm{~W}$ e report a case of a 41-year-old female patient with a positive serology of active EBV infection devel oping acute recurrent laryngeal nerve palsy. The occurrence of recurrent laryngeal nerve palsy associated with EBV infection represents an extremely rare incidence. ${ }^{6}$

\section{CASE REPORT}

A 41-year-old Caucasian female was admitted to the internal medicine department due to an abnormal fatigue associated with fever, muscle pain, nonproductive cough. At the time of admittance, physical examination revealed mild cervical lymphadenopathy, discrete pharyngeal erythema, hoarseness and difficulty of swallowing. A $n$ adenotonsillectomy had been performed in early childhood. Neurological examination did not reveal any pathological findings. The hemogram showed atypical lymphocytosis (53\%), increased C-reactive protein (41.4) and elevated liver transaminases. Chest $X$-ray demonstrated upper pulmonary infiltrations in terms of pneumonia without any signs of pleural effusion. A bdominal sonography revealed mild splenomegaly without any sign of hepatomegaly. Standard electrocardiogram and echocardiogram were normal. Due to the chest X-ray, the diagnosis of acute bronchitis with pneumonia was made, and the patient was treated intravenously with antibiotics (clarithromycine), antipyretic and antitussive medication. Because of atypical lymphocytosis, a M onospot test ${ }^{\circledR}$ along with immunologic studies were performed revealing elevated anti-EBV capsid antigen titers for both IgG and IgM. A ntibodies to cytomegal ie virus (CM V) and human immune deficiency virus (HIV) were not detectable. Hepatitis serology and pregnancy testing were negative. Blood culture showed no bacterial growth. The diagnosis of infectious mononucleosis was made.

The patient's general condition improved under the abovementioned therapy. However, the patient developed progressive hypophonia 10 days after hospitalization. When transferred to the ENT department, fiberoptic videolaryngoscopy with stroboscopy showed complete paralysis of the left vocal cord in abduction with abundant secretions, consistent with unilateral recurrent laryngeal nerve paralysis. The pharynx presented mild pharyngitis; the rest of the ENT examination, including CT scan and M RT, was normal. There were no radiological findings of any tumor involvement. The patient was presented to a speech pathologist; speech therapy was immediately initiated leading to complete recovery within a period of 3 months. Six months follow-up was uneventful without any impairment of the patient's general health condition and perfect speech condition. 
Epstein-Barr Virus Infection associated with Acute Recurrent Laryngeal Nerve Palsy

\section{DISCUSSION}

Epstein-Barr virus belongs to the group of human herpes viruses and can cause the clinical syndrome of infectious mononucleosis. The diagnosis of acute infectious mononucleosis should also take into consideration acute CM V infection, toxoplasma gondii (TG) infection and acute HIV infection. These diseases are clinically very similar by their signs and symptoms. However, in pregnant women, differentiation of mononucleosis from toxoplasmosis is associated with significant consequences for the fetus. ${ }^{7}$ Therefore, when dealing with pregnant women, detailed serological testing should be performed. ${ }^{8}$ In our patient, negative pregnancy testing ruled out this physical condition. Other conditions from which to distinguish infectious mononucleosis include leukemia, tonsillitis, diphtheria, common cold and influenza (the flu). ${ }^{9}$ Our patient presented neither clinical symptoms of tonsillitis nor positive testing for CM V, HIV , TG or diphtheria.

It has been reported that in $5 \%$ of patients suffering from acute EBV infection neurological symptoms can occur. ${ }^{10}$ The association between laryngeal paralysis and EBV infection has been well documented in cases of polyneuritis. ${ }^{11}$ However, cranial nerve deficits are rare and have been infrequently reported. ${ }^{12} \mathrm{~T}$ o our knowledge, recurrent laryngeal nerve palsy in EBV acutely infected patients has been reported only once with a case of bilateral laryngeal nerve palsy. ${ }^{6}$ Our patient presented the typical findings of failure of vocal cord adduction resulting in hypophonia. The vocal cord pal sy occurred 12 days after appearance of fatigue symptoms. We hypothesize that EBV infection as extracranial infection may have affected the vocal cord mediating cricoarytenoid muscles inducing vocal cord palsy. It has been reported that failure of the cricoarytenoid muscles can induce vocal cord paralysis. ${ }^{13}$ Interestingly, our patient suffered from unilateral cord pal sy without any findings of tumor involvement or history of previous surgery. Immediate speech therapy resulted in full recovery. Because disease development and prognosis depend on the cause and on the amount of paralysis, a detailed patient history with profound diagnostic analysis and with radiological as well as serological testing are essential. I mmediate speech therapy is recommended to minimize the risk of permanent vocal cord paralysis.

\section{CONCLUSION}

In cases of vocal cord paralysis and hypophonia, the possibility of EBV infection should be taken into account as an extremely rare differential diagnosis. Patients with these findings should be presented to a speech pathologist. To minimize the risk of permanent palsy, immediate speech therapy is recommended.

\section{CONSENT}

Written informed consent was obtained from the patient for publication of this case report and accompanying images. A copy of the written consent is available for review by the Editorin-Chief of this journal.

\section{AUTHOR'S CONTRIBUTIONS}

HPS, LUS, HS performed the literature research and composed the manuscript.

\section{REFERENCES}

1. A nderson MD, Kennedy CA, Lewis AW, Christensen GR. Retrobulbar neuritis complicating acute Epstein-Barr virus infection. Clin Infect Dis 1994;18:799-801.

2. Connelly KP, de Witt LD. Neurological complications of infectious mononucleosis. Pediatr Neurol 1994;10:181-84.

3. Grose C, H enle W, Henle P, Feorino PM . Primary Epstein-B arr virus infection in acute neurologic disease. N Engl J Med 1975;292:392-95.

4. Fleischer G, Schwartz J, L enette E. Primary E pstein-B arr virus infection in association with Reye syndrome. J Pediatr 1980;97:935-37.

5. Leavell R, Ray CG, Ferry PC, M innich LL. U nusual acute neurologic presentation with Epstein-Barr virus infection. A rch Neurol 1986;43:186-88.

6. Parano E, Pavone L, M usumeci S, Giambusso F, Trifiletti RR. A cute palsy of the recurrent laryngeal nerve complicating Epstein-B arr virus infection. N europediatr 1996;27:164-66.

7. Ebell MH. Epstein-Barr virus infectious mononucleosis. A m Fam Physician Oct 1, 2004;70(7):1279-87.

8. Gulley M L. M olecular diagnosis of E pstein-B arr virus-related diseases. J Mol Diagn Feb 2001;3(1):1-10.

9. Luzuriaga K, Sullivan JL. Infectious mononucleosis. N Engl J M ed 7, 2010;362(21):1993-2000.

10. Schooley RT. Epstein-B arr virus infections, including infectious mononucleosis. In: Harrison's Principles of Internal M edicine (13th ed). I ssel bacher K (Ed). New Y ork, M c Graw-Hill 1994; 1573-78.

11. Sharma KR, Sriram S, Fries T, B evan HJ, Bradley WG. $L$ umbosacral radiculoplexopathy as a manifestation of EpsteinBarr virus infection. Neurology 1993;43:2550-54.

12. Connolly M, Lunker AK, Chan K W, Farrel K. Cranial neuropathy, polyneuropathy and thrombocytopenia with EpsteinBarr virus infection. Dev M ed Child Neurol 1994;36:1010-15.

13. Dej ong RN . The neurologic examination. In: Dej ong RN (Ed), The Neurologic Examination (4th ed). Harper and Row: Baltimore 1979;446-50. 